NASA/CR-2003-211823

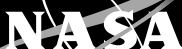

Measurement and Correlation of Ice Accretion Roughness

David N. Anderson

Ohio Aerospace Institute, Brook Park, Ohio

Daniel B. Hentschel

Rochester Institute of Technology, Rochester, New York

Gary A. Ruff

Drexel University, Philadelphia, Pennsylvania 
Since its founding, NASA has been dedicated to the advancement of aeronautics and space science. The NASA Scientific and Technical Information (STI) Program Office plays a key part in helping NASA maintain this important role.

The NASA STI Program Office is operated by Langley Research Center, the Lead Center for NASA's scientific and technical information. The NASA STI Program Office provides access to the NASA STI Database, the largest collection of aeronautical and space science STI in the world. The Program Office is also NASA's institutional mechanism for disseminating the results of its research and development activities. These results are published by NASA in the NASA STI Report Series, which includes the following report types:

- $\quad$ TECHNICAL PUBLICATION. Reports of completed research or a major significant phase of research that present the results of NASA programs and include extensive data or theoretical analysis. Includes compilations of significant scientific and technical data and information deemed to be of continuing reference value. NASA's counterpart of peerreviewed formal professional papers but has less stringent limitations on manuscript length and extent of graphic presentations.

- TECHNICAL MEMORANDUM. Scientific and technical findings that are preliminary or of specialized interest, e.g., quick release reports, working papers, and bibliographies that contain minimal annotation. Does not contain extensive analysis.

- CONTRACTOR REPORT. Scientific and technical findings by NASA-sponsored contractors and grantees.
- CONFERENCE PUBLICATION. Collected papers from scientific and technical conferences, symposia, seminars, or other meetings sponsored or cosponsored by NASA.

- SPECIAL PUBLICATION. Scientific, technical, or historical information from NASA programs, projects, and missions, often concerned with subjects having substantial public interest.

- TECHNICAL TRANSLATION. Englishlanguage translations of foreign scientific and technical material pertinent to NASA's mission.

Specialized services that complement the STI Program Office's diverse offerings include creating custom thesauri, building customized databases, organizing and publishing research results ... even providing videos.

For more information about the NASA STI Program Office, see the following:

- Access the NASA STI Program Home Page at http://www.sti.nasa.gov

- E-mail your question via the Internet to help@sti.nasa.gov

- Fax your question to the NASA Access Help Desk at 301-621-0134

- Telephone the NASA Access Help Desk at 301-621-0390

- Write to:

NASA Access Help Desk

NASA Center for AeroSpace Information 7121 Standard Drive

Hanover, MD 21076 
NASA/CR-2003-211823

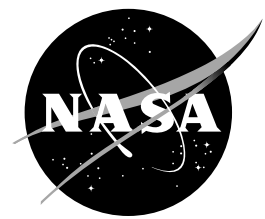

\section{Measurement and Correlation of Ice Accretion Roughness}

David N. Anderson

Ohio Aerospace Institute, Brook Park, Ohio

Daniel B. Hentschel

Rochester Institute of Technology, Rochester, New York

Gary A. Ruff

Drexel University, Philadelphia, Pennsylvania

Prepared for the

36th Aerospace Sciences Meeting and Exhibit

sponsored by the American Institute of Aeronautics and Astronautics

Reno, Nevada, January 12-15, 1998

Prepared under Cooperative Agreement NCC3-884

National Aeronautics and

Space Administration

Glenn Research Center 


\section{Acknowledgments}

This work was partially supported by NASA Glenn through grant NAG3-2043.

The authors wish to thank Paul Cvar for assistance in analyzing the photographic images and Steve Fennell for reviewing alternate correlations of the smooth-zone width data.

This report contains preliminary

findings, subject to revision as analysis proceeds.

Trade names or manufacturers' names are used in this report for identification only. This usage does not constitute an official endorsement, either expressed or implied, by the National Aeronautics and Space Administration.

The Aerospace Propulsion and Power Program at NASA Glenn Research Center sponsored this work.

Available from

NASA Center for Aerospace Information 7121 Standard Drive

Hanover, MD 21076
National Technical Information Service 5285 Port Royal Road Springfield, VA 22100 


\author{
MEASUREMENT AND CORRELATION OF ICE ACCRETION ROUGHNESS \\ David N. Anderson* \\ Ohio Aerospace Institute \\ Brook Park, Ohio 44142 \\ Daniel B. Hentschel ${ }^{\dagger}$ \\ Rochester Institute of Technology \\ Rochester, New York 14623 \\ Gary A. Ruff \\ Drexel University \\ Philadelphia, Pennsylvania 19104
}

\begin{abstract}
$\underline{\text { Abstract }}$
Measurements were taken of the roughness characteristics of ice accreted on NACA 0012 airfoils in the NASA Lewis Icing Research Tunnel (IRT). Tests were conducted with size scaled, using models with chords of 26.7, 53.3 and $80.0 \mathrm{~cm}$, and with liquid-water content scaled, both according to previously-tested scaling methods. The width of the smooth zone which forms on either side of the leading edge of the airfoil and the diameter of the roughness elements are presented in non-dimensional form as functions of the accumulation parameter. The smooth-zone width was found to decrease with increasing accumulation parameter. The roughness-element diameter increased with accumulation parameter until a plateau was reached. This maximum diameter was about .06 times twice the model leading-edge radius. Neither smoothzone width nor element diameter were affected by a change in freezing fraction from .2 to .4. Both roughness characteristics appeared to scale with model size and with liquid-water content.
\end{abstract}

\section{Nomenclature}

$A_{c} \quad$ Accumulation parameter, dimensionless

$b \quad$ Relative heat factor, dimensionless

$c_{p, a} \quad$ Specific heat of air, cal/g K

$c_{p, w} \quad$ Specific heat of water, cal/g K

$d \quad$ Roughness-element diameter, $\mathrm{mm}$

evap Evaporation terms in energy equation, ${ }^{\circ} \mathrm{C}$

$h_{c} \quad$ Convective heat-transfer coefficient, $\mathrm{cal} / \mathrm{s} \mathrm{cm}^{2} \mathrm{~K}$

*Icing Consultant, member AIAA

${ }^{\dagger}$ Student

*Associate Professor, Associate Fellow AIAA
LWC Cloud liquid-water content, $\mathrm{g} / \mathrm{m}^{3}$

MVD Water droplet median volume diameter, $\mu \mathrm{m}$

$n \quad$ Freezing fraction, dimensionless

$r \quad$ Recovery factor, dimensionless

$R \quad$ Airfoil leading-edge radius, $\mathrm{mm}$

$V \quad$ Airspeed, $\mathrm{m} / \mathrm{s}$

$t_{f} \quad$ Freezing temperature of water, ${ }^{\circ} \mathrm{C}$

$t_{\text {surf }} \quad$ Temperature at surface of ice, ${ }^{\circ} \mathrm{C}$

$t_{s t} \quad$ Static temperature, ${ }^{\circ} \mathrm{C}$

$w \quad$ Smooth-zone width, $\mathrm{mm}$

$\beta_{0} \quad$ Stagnation-zone droplet collection efficiency, dimensionless

$\phi \quad$ Droplet energy transfer terms in energy balance, ${ }^{\circ} \mathrm{C}$

$\Lambda_{f} \quad$ Latent heat of freezing of water, cal $/ \mathrm{g}$

$\rho_{l} \quad$ Ice density, $\mathrm{g} / \mathrm{m}^{3}$

$\theta \quad$ Air energy transfer terms in energy balance, ${ }^{\circ} \mathrm{C}$

$\tau \quad$ Accretion time, $\mathrm{s}$

\section{Introduction}

This paper presents the results of measurements of ice roughness formed during icing tests in the NASA Lewis Icing Research Tunnel (IRT). NACA 0012 airfoils were tested at glaze-ice conditions. Correlations of the data using non-dimensional icing parameters will be presented.

An improved understanding and characterization of roughness features contributes to aircraft design for icing in two ways. First, analytical ice-accretion prediction codes such as LEWICE ${ }^{1}$ use estimates of the convective heat transfer rate in performing a heat balance at the ice surface. An improved description of roughness characteristics along with a better 
understanding of the effect of roughness on heat transfer would permit more accurate ice-accretion codes. Second, it has been shown ${ }^{2}$ that roughness resulting from even short exposures to icing can lead to a significant reduction in stall margin. Both flight and tunnel tests are performed using artificial roughness to determine its effect on performance. However, there is currently very little information about roughness characteristics or how these characteristics are affected by cloud conditions. Improved knowledge would permit testing with artificial roughness that more closely simulates natural ice.

For glaze-ice conditions, when super-cooled water impinges on an airfoil, freezing is not instantaneous. As freezing takes place, a smooth ice cap is formed around the leading edge; at some chord-wise distance downstream from the stagnation line, there is a transition from smooth to rough ice. Olsen and Walker, ${ }^{3}$ using high-speed motion pictures, found that in the rough zone, water which did not freeze immediately coalesced to form nearly-hemispherical beads. These beads grew with continued exposure to the icing spray, eventually freezing in closely-spaced arrays. This observation led them to question the longaccepted model first used by Messinger ${ }^{4}$ in which unfrozen water ran back along the model surface. Hansman, Reehorst and Sims ${ }^{5}$ used high-speed video to expand on the work of Olsen and Walker; they observed that water beads grew until their size was sufficient to be influenced by aerodynamic forces. When a critical size was reached, the bead was swept downstream.

Hansman and Turnock ${ }^{6}$ studied the development of surface roughness characteristics during an icing spray on a cylinder and recorded the location of transition from smooth to rough zones. Shin ${ }^{7}$ performed icing tests with an NACA 0012 airfoil and obtained values for smooth-zone width and roughness-element diameter, height and spacing. Other studies have investigated the effects of roughness on the boundary layer ${ }^{8,9}$ and on convective heat transfer. ${ }^{9-11}$

Shin's data were shown by Anderson and $\mathrm{Shin}^{12}$ to correlate with the dimensionless icing parameters, accumulation parameter and freezing fraction. In reference 12 it was postulated that high freezing rates (represented by high freezing fractions) prevented water beads from growing very large before freezing, while high rates of water impingement (high accumulation parameters) tended to permit water beads to grow fairly large before freezing.

The present study had two objectives: first, to obtain additional roughness data to check the validity of the correlations of reference 12 , and, second, to determine if roughness features scale with model size or with liquid-water content when appropriate scaling methods are used. NACA 0012 airfoils with chords of 26.7, 53.3 and $80.0 \mathrm{~cm}$ were tested with glaze-ice conditions for icing times from $14-810$ sec. The ice roughness characteristics were recorded photographically for later analysis. The ice roughness element diameters and smooth-zone widths obtained from those images will be reported.

\section{$\underline{\text { Icing Parameters }}$}

Two dimensionless parameters will be used in presenting and discussing the results. They are the accumulation parameter, $A_{c}$, and the freezing fraction, $n$.

The accumulation parameter is proportional to the rate at which water impinges and to the icing time. It is given by

$$
A_{c}=\frac{V \cdot L W C \cdot \tau}{2 R \cdot \rho_{i}}
$$

The freezing fraction was defined by Messinger ${ }^{4}$ as the fraction of water which freezes in the region of impingement. If an energy balance is made at the leading edge of a model exposed to an icing cloud, $n$ is found to be:

$$
n=\frac{c_{p, w}}{\Lambda_{f}}\left(\phi+\frac{\theta}{b}\right)
$$

where $\phi$ is a collection of terms in the energy balance which represent the droplet energy transfer:

$$
\phi=t_{f}-t_{s t}-\frac{V^{2}}{2 c_{p, w}}
$$

and $\theta$ collects the air energy transfer terms:

$$
\theta=t_{\text {surf }}-t_{s t}-r \frac{V^{2}}{2 c_{p, a}}+e v a p
$$

where evap is the water-evaporation term which is typically small. Both $\phi$ and $\theta$ have units of temperature. The dimensionless relative heat factor, $b$, is

This is the ratio of the heat carried to the surface by impinging water to that convected away by the airstream. 


\section{Description of Experiments}

NASA Lewis Icing Research Tunnel The IRT is shown in Figure 1. A full description of the tunnel as it was before recent improvements in the spray system is given in reference 13 . The IRT has a test section width of $2.7 \mathrm{~m}(9 \mathrm{ft})$ and a height of $1.8 \mathrm{~m}(6 \mathrm{ft}$.) With an assumed test-section blockage of $5 \%$ it is capable of operating at airspeeds up to $160 \mathrm{~m} / \mathrm{s}$ (350 mph). A refrigeration system permits accurate control of the test-section temperature from -30 to $1^{\circ} \mathrm{C}\left(-20\right.$ to $\left.33^{\circ} \mathrm{F}\right)$ within $\pm .5^{\circ} \mathrm{C}\left( \pm 1^{\circ} \mathrm{F}\right)$.

The water-spray system consisted of 8 spray bars. The system was calibrated to provide controlled test-section liquid-water content, $L W C$, from 0.2 to $3 \mathrm{~g} / \mathrm{m}^{3}$ and droplet median volume diameter, $M V D$, from 15 to $40 \mu \mathrm{m}$. The wide range of liquid-water content in the IRT is possible through the use of two spray nozzle sets, the mod-1 and standard nozzles ${ }^{13}$. Only the mod-1 nozzles were used in the studies reported here.

Test Models All tests were performed using unswept NACA 0012 airfoils mounted vertically in the center of the IRT test section. Reference tests were performed with a 1.8-m-span, 53.3-cm-chord model. A one-halfsize model with a $26.7-\mathrm{cm}$ chord and a one-and-onehalf-size model with an $80-\mathrm{cm}$ chord were also tested. The leading-edge radii, $R$, of the models were estimated to be $4.19,8.38$ and $12.57 \mathrm{~mm}$ for the $26.7-, 53.3-$ and 80.0-cm-chord models, respectively. The $1 / 2$ - and $1 \frac{1}{2}$ scale models had a 1.2-m span and were mounted on a stand such that the mid-span of the model was at the center of the test section. All models were mounted with a $0^{\circ}$ angle of attack. All measurements were made within a few centimeters of the mid-span of the model.

To permit the IRT spray-bar conditions to reach steadystate before exposing the model to the icing cloud, a fabric shield was attached to the front of each model as described in reference 12 . Once the spray had stabilized, the shield was rapidly drawn through a small port in the ceiling of the test section. The fabric shield made no apparent change in the model blockage; thus, it was not necessary to adjust the test-section velocity when the shield was removed.

Test Procedure The shield was placed on the model before starting the tunnel fan. Tests were performed by first establishing the desired test-section velocity and temperature. Water spray was then initiated. The shield was pulled from the model when the spray conditions had stabilized, and the spray was timed with a handheld stop watch from the removal of the shield.

At the completion of the prescribed spray time, the tunnel was brought to idle and the test section entered.
Close-up 35-mm photographs of the resulting ice at the span-wise tunnel centerline were taken from three views of the model: front, left side and right side. These photographs were later scanned and the digital image recorded on $\mathrm{CD}$ for analysis. The analysis procedure is described below.

After the photographs were taken, the model was cleaned and the procedure repeated for the next spray. Thus, successive tests to determine the effects of time on roughness characteristics were always made by starting with a clean model rather than adding to the accretion from the previous run.

\section{Test Conditions}

Average test conditions for each run are shown in Table I. Two test series were run: Series A was designed to have a freezing fraction of 0.2 , and series $\mathrm{B}$ a freezing fraction of 0.4. The actual test conditions produced freezing fractions slightly different from these goals.

Size Scaling Within each series tests were performed with model sizes of 26.7-, 53.3- and 80.0-cm chord. The 53.3-cm-chord model was chosen as the reference, and the test conditions for the $26.7-\mathrm{cm}$ $(1 / 2$-size $)$ and 80.0 -cm (1 1/2-size) models were calculated by applying the constant-Weber-number scaling $\operatorname{method}^{14}$. This method was developed to scale watersurface dynamics and has had some success in scaling ice shapes. ${ }^{14,15}$ It matches the droplet trajectories, accumulation parameter, Weber number and heat balance parameters, including the freezing fraction, between the scale and the reference tests. The constantWeber-number method is based on the AEDC method, ${ }^{16}$ but the latter does not require that the scale Weber number match the reference. The AEDC method has also been successful in scaling ice shapes. ${ }^{16,17}$ Reference tests were made on 5-29-96 and repeated on 6-5-96 for test series A. Reference tests for test series B were made on 5-29-96 and repeated on 6-10-96. Scaled tests with the 26.7-cm model were made on 6-3-96, and scaled tests with the $80.0-\mathrm{cm}$ model, on 6-17-96.

LWC Scaling Reference tests were performed with a liquid-water content of $0.6 \mathrm{~g} / \mathrm{m}^{3}$. The reference tests for size scaling also served as reference for $L W C$ scaling. Tests with $L W C$ scaled to $1 \mathrm{~g} / \mathrm{m}^{3}$ with the $53.3-\mathrm{cm}$-chord model were made on 5-30-96 for both test series. The Olsen method ${ }^{18}$ was used to determine scaled test conditions for $L W C$ scaling. This method matches the reference accumulation parameter, freezing fraction, droplet size and airspeed and has been shown to scale ice shapes effectively for different $L W C$ 's. ${ }^{18}$ 


\section{Roughness Data Analysis}

An area approximately 15 to $20 \mathrm{~mm}$ square from each close-up photograph of ice roughness was scanned at high resolution to produce a digital record which was then stored on CD ROM for later analysis. Figure 2 is a sample image reproduced from one digital record. It is a front view of a portion of the airfoil after approximately $2 \mathrm{~min}$ of ice accretion. It shows the smooth zone, the rough zone, typical roughness elements and a typical element diameter. Each image included a portion of a calibration scale which was held on the model while the photographs were made. The lines on the scale were $1 \mathrm{~mm}$ apart. These divisions provided the length calibration for the image-analysis software $\left(\operatorname{SigmaScan}{ }^{\mathrm{TM}}\right)$. Using the calibration, the software assigned a length to lines drawn on the image and recorded each length in a table. Because the model curves away from the camera lens on each side, the calibration changes across the image. Consequently, feature sizes were based on calibrating to that part of the scale vertically in line with the feature.

It is evident from figure 2 that the smooth-zone width experienced small variations along the span. In general, measurements at 10 to 50 locations along the span were adequate to define the width. For some cases, only two widths were recorded: a minimum and a maximum value were sufficient to represent the minor variations observed. Values reported will be the averages of the observed measurements.

The roughness elements were measured at or near the smooth-zone boundary. They varied widely in size. Consequently, the diameters of a large number of elements (often several hundred) were required to determine the statistics needed to characterize the roughness elements. For many of the test runs, element diameters obtained from more than one image from the same run were included in the average.

Measurement Repeatability Not all of the images were as clear as that shown in figure 2 . In some, details could not be seen well, and these images were not used. Even when features could be seen, roughness element edges and smooth-zone boundaries had to be inferred from the light and dark patterns in the image. Because of the role of judgement in defining the size of elements, many of the images were analyzed by two researchers working independently. Some were also re-analyzed by one of the researchers after a two-month delay. In general, the smooth-zone widths from these different sessions agreed within $\pm 5 \%$.

The element diameters did not always agree so well. Figure 3 (a) compares three separate analyses of the same images from one sequence of tests. Each symbol is the average diameter, and the error bars represent the standard deviations. Diameters recorded by the first researcher tended to be higher than those found by the second. The mean diameter found in each analysis would have been affected by such subjective factors as judging the location of the roughness element edges and deciding whether to include small features, which might or might not be roughness elements. The size of the smallest features was also very difficult to define.

Hemispherical roughness elements should appear as circles when viewed from above. To compare the chord-wise diameter with the span-wise, the two diameters were recorded separately for some of the images. Figure 3(b) shows results from one set of tests for which this was done. In many cases the span-wise diameter tended to be larger than the chord-wise. Because of the curvature of the model in the chord-wise direction, elements were sometimes viewed at a small angle such that the calibration would have been more accurate when applied to the span-wise measurement. Nevertheless, the reported diameters typically will be the averages of the chord-wise and the span-wise diameters. Only in a few cases was the difference between the two measurements large enough that only the span-wise diameter was used.

Size Distribution Smooth-zone widths from each image were averaged and the standard deviation calculated. Because the variation in width was relatively small over the span, the distribution of these dimensions was not investigated.

The roughness-element diameters found from all analyses of the images for a given test run were combined into a single data set. Histograms of each of these resulting sets of roughness-element diameter were examined and most were found to approximate gaussian distributions. Fig. 4 shows two such nearlygaussian examples. The vertical bars in this figure show the measured element diameters and the solid line is a gaussian distribution with the same mean and standard deviation as the experimental data. The data sets resulting from the clearest images were fairly large (hundreds of measurements) and tended towards this distribution. Data sets from poorer-quality images had fewer members and often had a flat or bimodal distribution. There was less confidence in the nongaussian distributions because elements of sizes important to the distribution may not have been included. Thus, only diameters from data sets with near-gaussian distributions will be reported.

\section{Uncertainty Analysis}

Smooth-Zone Width Errors in the reported smooth-zone width would have included inaccuracies in the calibration scale, error in marking the ends of the 
calibration line and parallax error caused by applying a given calibration inappropriately to the image. These are together estimated to give an error of $\pm 5 \%$. For the widest smooth zones, the edge of the smooth-zone cannot be identified to an accuracy better than $\pm 1 \mathrm{~mm}$. This problem could account for an additional error of $\pm 2 \frac{1}{2} \%$.

Roughness-Element Diameter Errors in the reported roughness-element diameter include the same errors mentioned in connection with the smooth-zone width. These are together estimated to give an error of $\pm 5 \%$. Subjective error in defining the roughnesselement edge can be estimated by comparing the results from different analyses. For those cases for which duplicate analyses were made, the maximum uncertainty indicated was $\pm 20 \%$ (see fig. 3 ). This error would tend to include some of the scale uncertainties, so the maximum error in the reported diameters should be close to $\pm 20 \%$.

$\underline{\text { Tunnel Conditions }}$ Tunnel temperatures, velocities and spray-bar conditions were recorded at 2-s intervals during each test. Each of the parameters was averaged over the spray period to obtain the reported conditions. Considering the variations during the run as well as possible instrument error, the total uncertainty in temperature was estimated to be about $\pm 2.5^{\circ} \mathrm{C}$ $\left(4.5^{\circ} \mathrm{F}\right)$, in velocity, less than $\pm 4 \%$, in liquid-water content, less than $\pm 2.2 \%$, and in the median volume diameter, less than $\pm 12.7 \%$.

The recording of spray duration manually with a stop watch was estimated to be accurate to within $\pm 1 \mathrm{~s}$, or $\pm 8 \%$ for the shortest times. The uncertainty in spray time, velocity and liquid-water content would result in an uncertainty of less than $\pm 14.2 \%$ in the accumulation parameter. This maximum uncertainty would have decreased as accumulation parameter increased.

\section{$\underline{\text { Results }}$}

Table I includes the mean and standard deviation of the smooth-zone width and roughness-element diameter from each acceptable data set. In addition, the standard deviation, number of data readings taken, the minimum value and the maximum value for each data set are also given in the table.

Smooth-Zone Width Figure 5 is a plot of the dimensionless average width as a function of the accumulation parameter, $A_{c}$. The widths were normalized with respect to twice the leading-edge radius of the model. Data for test series $\mathrm{A}(n \sim 0.2)$ is shown with open symbols and data for test series $\mathrm{B}$ ( $n$ $\sim 0.4$ ) is given with solid symbols. The repeatability of the data can be appreciated by comparing 5-29-96 data with 6-5-96 for test series A and 5-29-96 with 6-1096 for test series B. Repeatability was especially poor for the shortest accretion times (low accumulation parameters) where the smooth-zone width was large.

Data for tests with $L W C$ scaled were obtained on 5-30-96. The dimensionless smooth-zone widths with $L W C$ scaled were consistent with the other test data. Similarly, dimensionless widths from the size-scaled tests on 6-3-96 and 6-17-96 did not appear to be significantly different from the reference nondimensional widths or scaled- $L W C$ values. These results suggested that when scaling methods were used, the smooth-zone width for a given accumulation parameter maintained similarity.

The solid line on the figure is the correlation from reference 12 which was based on data by Shin ${ }^{7}$ using a 53.3-cm-chord NACA 0012 airfoil tested at a freezing fraction of $\sim 0.3$. The fairly limited data in references 7 and 12 suggested that the smooth-zone width decreased linearly with accumulation parameter. The present results showed an apparent exponential decline of width with accumulation parameter, but for $A_{c}>.4$ the widths were generally consistent with those measured by Shin. Note that $A_{c}$ used in reference 12 was calculated using a leading-edge radius of $12.7 \mathrm{~mm}$ while the present study used 8.38. The accumulation parameters for the reference-12 data have been corrected to be consistent with the present study.

Although not shown, the widths found in this investigation were also consistent with widths calculated from Hansman's reported smooth-rough transition on a cylinder ${ }^{6}$ at a temperature of $-4.5^{\circ} \mathrm{C}$. Hansman also reported smooth-rough transition locations for $-9{ }^{\circ} \mathrm{C}$, but the corresponding smooth-zone widths were more than double those of the present study. This effect of temperature found by Hansman would suggest a freezing-fraction effect. No effect of freezing fraction was apparent in the present study.

Element Diameter The mean roughnesselement diameters were normalized by dividing by $2 R$. The dimensionless diameter is shown as a function of the accumulation parameter in figure 6 . The error bars on the experimental points are the standard deviations for each data set.

Figure 6(a) compares dimensionless mean diameters for test series A. The element diameters tended to increase with accumulation parameter up to an $A_{c}$ of about 0.4 . Shin's data as reported in reference 12 showed a similar trend but reached a plateau at $A_{c} \sim 0.15$. The maximum diameter reported in reference 12 for a freezing fraction of 0.2 was $\sim 1.2 \mathrm{~mm}$; this diameter gives $d / 2 R=0.07$, a value about $17 \%$ higher than the maximum in 
figure 6(a). This difference was within the uncertainty in the present data.

Repeatability of the results from the 5-29-96 tests to the $6-5-96$ tests was poor. The element diameters resulting from the two sets of tests differed by nearly a factor of 2 at $A_{c}=0.06$. For $A_{c}=0.25$ the difference decreased to about $21 \%$.

Included in figure 6(a) are results from scaled tests for models of different size. Because of limited data, only results for the 53.3- and 80-cm-chord models could be compared and only for accumulation parameters less than 0.25. The non-dimensional roughness element diameter for the $80-\mathrm{cm}$ model was nearly equal to that for the 53.3-cm model tested on 6-5-96 at $A_{c}=0.06$, but was about $17 \%$ smaller at $A_{c}=0.24$. This difference was within the uncertainty in the present data, but was sufficiently large that scaling success was inconclusive.

Figure 6(b) gives results of liquid-water-content scaling for test series A. The reference test results, with a liquid-water content of $0.6 \mathrm{~g} / \mathrm{m}^{3}$, from 5-29-96 and 6-5-96 are repeated from figure 6(a). The roughnesselement diameters which resulted from sprays with an $L W C$ of $1 \mathrm{~g} / \mathrm{m}^{3}$ were obtained from tests on 5-30-97. These diameters exhibited the same trend with accumulation parameter as the reference data. For $A_{c}$ less than .14 , the $1-\mathrm{g} / \mathrm{m}^{3}$ diameters were approximately midway between the $.6-\mathrm{g} / \mathrm{m}^{3}$ reference data of 5-29-96 and those of 6-5-96. For $A_{c}$ greater than 0.14, the $1-\mathrm{g} / \mathrm{m}^{3}$ diameters were nearly the same as those from the 5-29-96 tests. For this study, then, a change in $L W C$ from .6 to $1 \mathrm{~g} / \mathrm{m}^{3}$ appeared to have no significant effect on the roughness element size when $L W C$-scaling methods were used.

Results from the size-scaling tests for test series B $(n \sim$ 0.4 ) are shown in figure 6(c). The normalized element diameter again was seen to increase with increasing accumulation parameter up to $A_{c} \sim 0.4$. For $A_{c}>0.4$, $d / 2 R$ appeared to reach a plateau of about 0.06 . This was the same trend and apparent plateau value evident in figs. 6(a) and 6(b) for test series $\mathrm{A}(n \sim .2)$. This consistency in results between test series A and B led to the conclusion that freezing fraction had no significant effect on element size for $n=0.2$ or $n=0.4$.

The absence of a freezing-fraction effect on roughness element size was in contrast to the findings of reference 12 where the roughness-element size was found to decrease about $20 \%$ when $n$ increased from 0.2 to 0.4 . The maximum diameter reported in reference 12 for a freezing fraction of 0.4 was $\sim 1 \mathrm{~mm}$; this diameter is equivalent to $d / 2 R=0.06$, a value consistent with the results of figure $6(\mathrm{c})$.

The normalized roughness-element diameters given in figure 6(c) appeared to be independent of model size for airfoils of chords from 26.7 to $80.0 \mathrm{~cm}$. Although the data were limited, these results at $n=.4$ suggested that element size scaled with the model size.

\section{Concluding Remarks}

Roughness characteristics were measured on NACA 0012 airfoil models with chords of 26.7, 53.3 and $80.0 \mathrm{~cm}$. Test conditions for the $26.7-$ and $80.0-\mathrm{cm}$ models were scaled from those for the $53.3-\mathrm{cm}$ reference tests. In addition, a number of tests were made with $L W C$ scaled from 0.6 to $1 \mathrm{~g} / \mathrm{m}^{3}$. The following general observations were made.

1. The smooth-zone width decreased with accumulation parameter. This general trend has been observed elsewhere (see refs. 6 and 12).

2. The roughness-element diameter increased with accumulation parameter until $d / 2 R$ reached a plateau of about 0.06 . The maximum $d / 2 R$ for this study was the same as that given in reference 12 for a freezing fraction of 0.4 , but about $17 \%$ lower than reported in reference 12 at a freezing fraction of 0.2 .

3. No effect of freezing fraction for freezing fractions of 0.2 and 0.4 was observed on either the smoothzone width or the roughness-element diameter. This absence of an effect of $n$ was in contrast to the observations of references 6 and 12 .

4. Although some of the size-scaling data were inconclusive, other data suggested that the dimensionless smooth-zone width, $w / 2 R$, and roughness-element diameter, $d / 2 R$, scaled with model size and also with $L W C$. Size-scaling and $L W C$-scaling methods were applied in the present tests.

5. The accumulation parameter appeared to be a suitable correlating parameter for both smoothzone width and roughness-element diameter, but additional data are needed to explore further the effect of freezing fraction and other possible correlating parameters.

Correlations of roughness characteristics, when combined with data on the effect of roughness on convective heat transfer, could be incorporated into iceaccretion-prediction codes to improve the ice-shape prediction. Information on roughness characteristics will also improve the simulation of ice roughness for wind-tunnel and flight tests of the effect of roughness on aerodynamic performance. 
The use of two-dimensional photographic images to obtain roughness data is subject to significant user interpretation. A less subjective technique of recording and measuring roughness characteristics is needed for future studies. Two alternate approaches which should be considered are molding of the ice accretion to preserve a three-dimensional image and threedimensional scanning to produce a digital image. Both methods should permit analyses which are more objective than the present approach.

\section{$\underline{\text { References }}$}

1. Ruff, G.A. and Berkowitz, B., “User's Manual for the NASA Lewis Ice Accretion Prediction Code LEWICE," NASA CR-185129, May 1990.

2. Brumby, R.E., "The Effect of Wing Ice Contamination on Essential Flight Characteristics," AGARD Conference Proceedings No. 496, Effects of Adverse Weather on Aerodynamics, 1991.

3. Olsen, W.A.. and Walker, E., "Experimental Evidence for Modifying the Current Physical Model for Ice Accretion on Aircraft Structures," NASA TM87184, 1987.

4. Messinger, B.L., "Equilibrium Temperature of an Unheated Icing Surface as a Function of Airspeed," J. Aeron. Sci. Vol. 20, No. 1, Jan. 1953, pp. 29-42.

5. Hansman, R. John, Jr., Reehorst, Andrew and Sims, James, "Analysis of Surface Roughness Generation in Aircraft Ice Accretion,” AIAA-92-0298, January, 1992.

6. Hansman, R.J., Jr. and Turnock, S.R., "Investigation of Surface Water Behavior During Glaze Ice Accretion," J Aircraft Vol. 26, No. 2, February 1989, pp. 140-147.

7. Shin, Jaiwon, "Characterization of Surface Roughness Associated with Leading Edge Ice Accretion," NASA TM-106459 and AIAA-94-0799, January, 1994.

8. Bragg, M.B., Kerho, M. and Cummings, M., "Airfoil Boundary Layer Due to Large Leading-Edge Roughness," AIAA-95-0536, January, 1995.
9. Bragg, M.B., Cummings, M.J., Lee, S. and Henze, C.M., "Boundary-Layer and Heat-Transfer Measurements on an Airfoil with Simulated Ice Roughness," AIAA-96-0866, January, 1996.

10. Henry, R.C., Hansman, R.J., Jr. and Breuer, K.S., "Heat Trensfer Variation on Protuberances and Surface Roughness Element," J. Thermophysics and Heat Transfer, Vol. 9, No. 1, January-March, 1995, pp. $175-180$.

11. Dukhan, Nihad, Van Fossen, G. James, Jr., Masiulaniec, K. Cyril and DeWitt, Kenneth J., "Convective Heat Transfer Coefficients from Various Types of Ice Roughened Surfaces in Parallel and Accelerated Flow," AIAA-96-0867, January, 1996.

12. Anderson, David N. and Shin, Jaiwon, "Characterization of Ice Roughness from Simulated Icing Encounters," NASA TM-107400 and AIAA-970052, January, 1997.

13. Soeder, Ronald H., Sheldon, David W., Andracchio, Charles, R., Ide, Robert F., Spera, David A. and Lalli, Nick M., "NASA Lewis Icing Research Tunnel User Manual," NASA TM-107159, June 1996.

14. Bilanin, Alan J. and Anderson, David N.: "Ice Accretion with Varying Surface Tension," AIAA-950538 and NASA TM-106826, January, 1995.

15. Anderson, David N., "Evaluation of ConstantWeber-Number Scaling for Icing Tests," AIAA-960636 and NASA TM-107141, January, 1996.

16. Ruff, G.A., "Analysis and Verification of the Icing Scaling Equations," AEDC-TR-85-30, Vol. 1 (Rev), March, 1986.

17. Anderson, David N., "Further Evaluation of Traditional Icing Scaling Methods," AIAA-96-0633 and NASA TM-107140, January, 1996.

18. Anderson, David N., "Methods for Scaling Icing Test Conditions," AIAA-95-0540 and NASA TM-106827, January, 1995. 


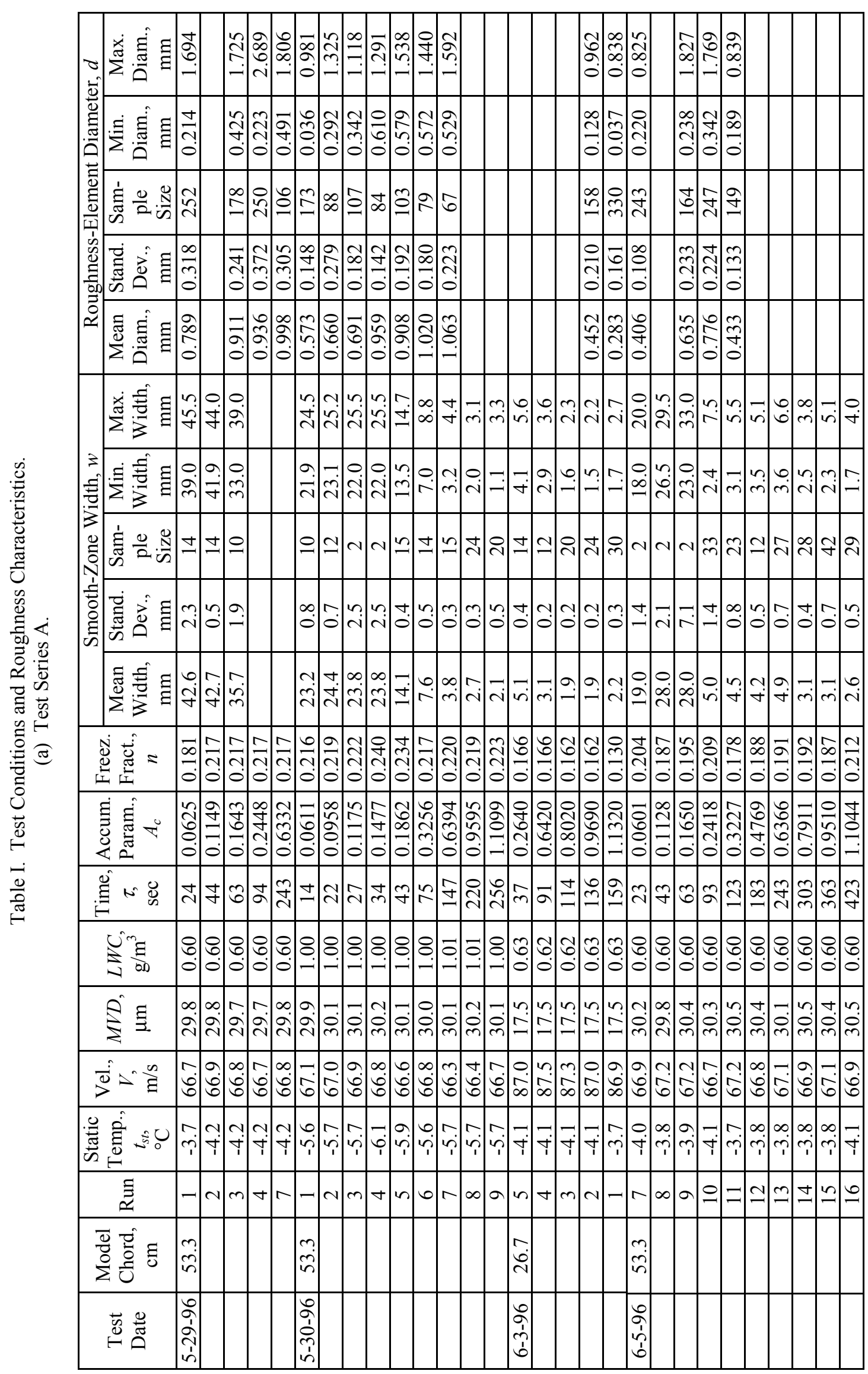




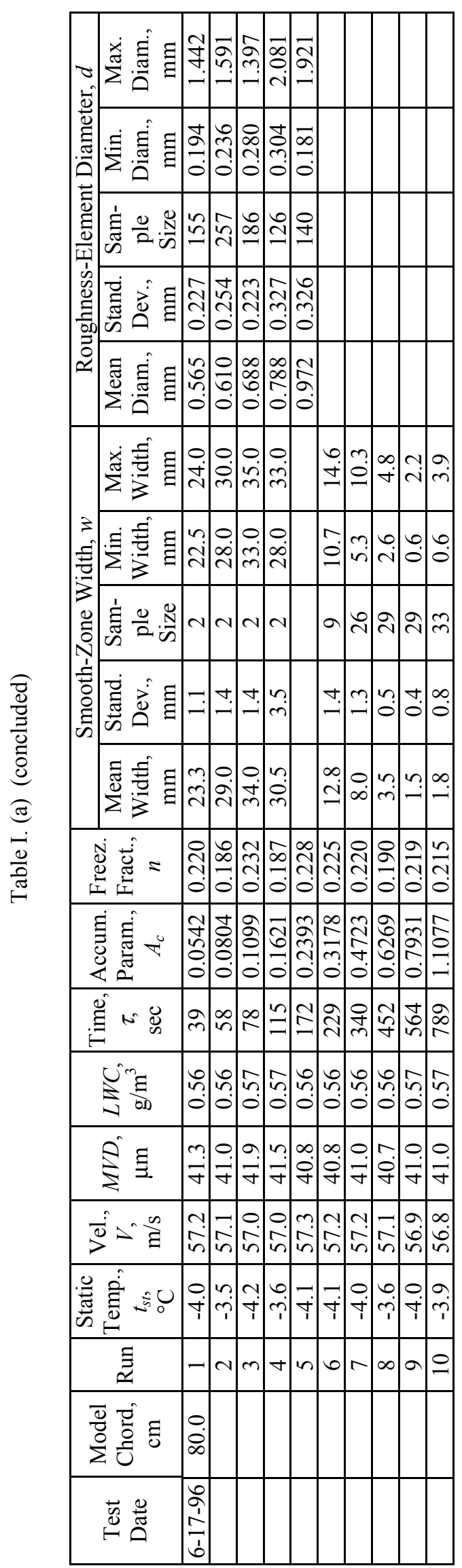




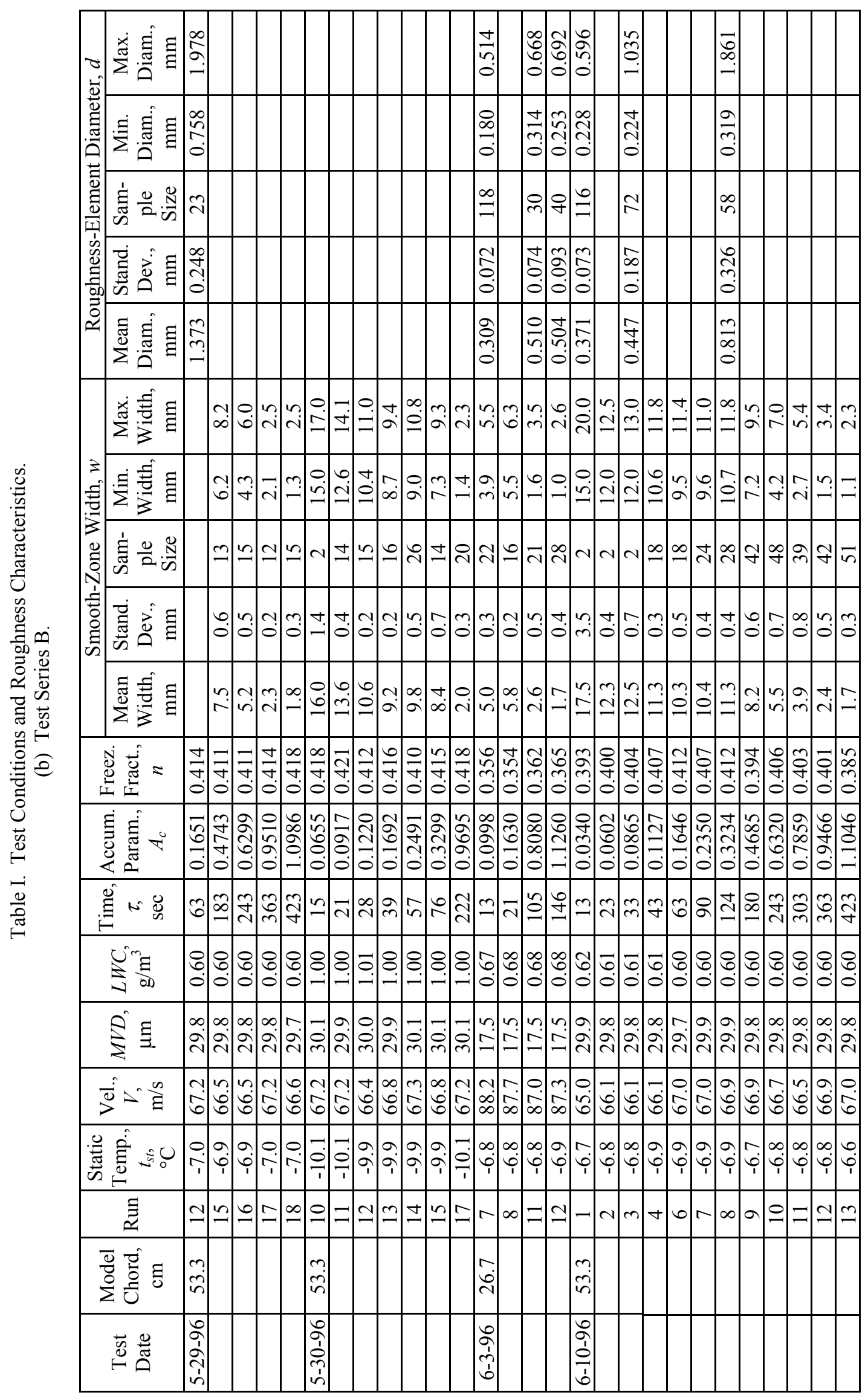




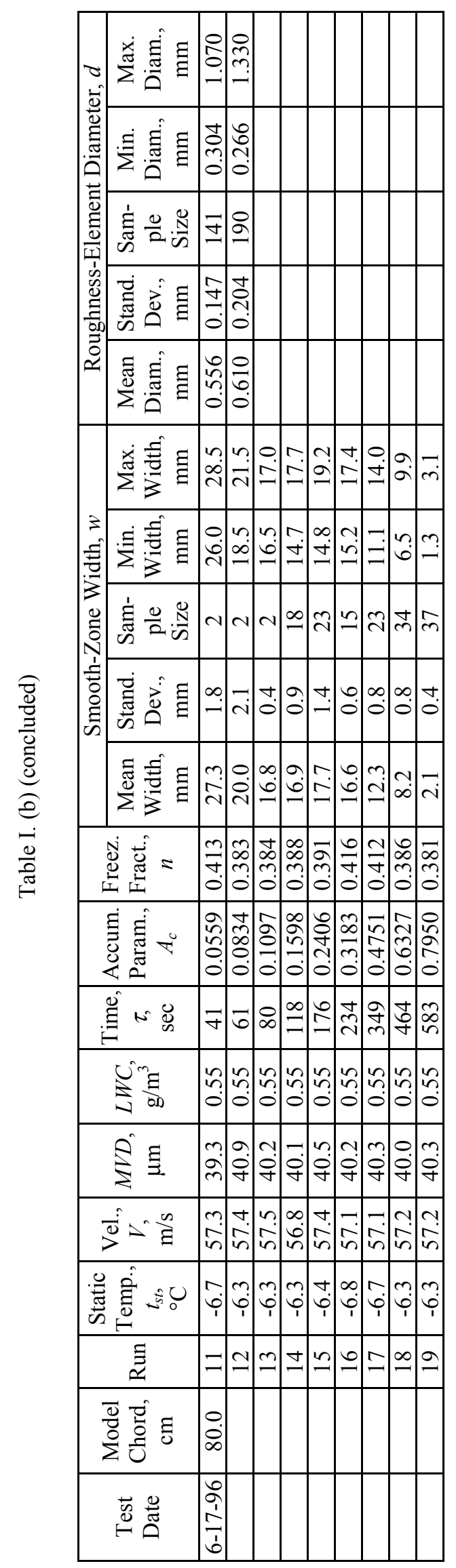



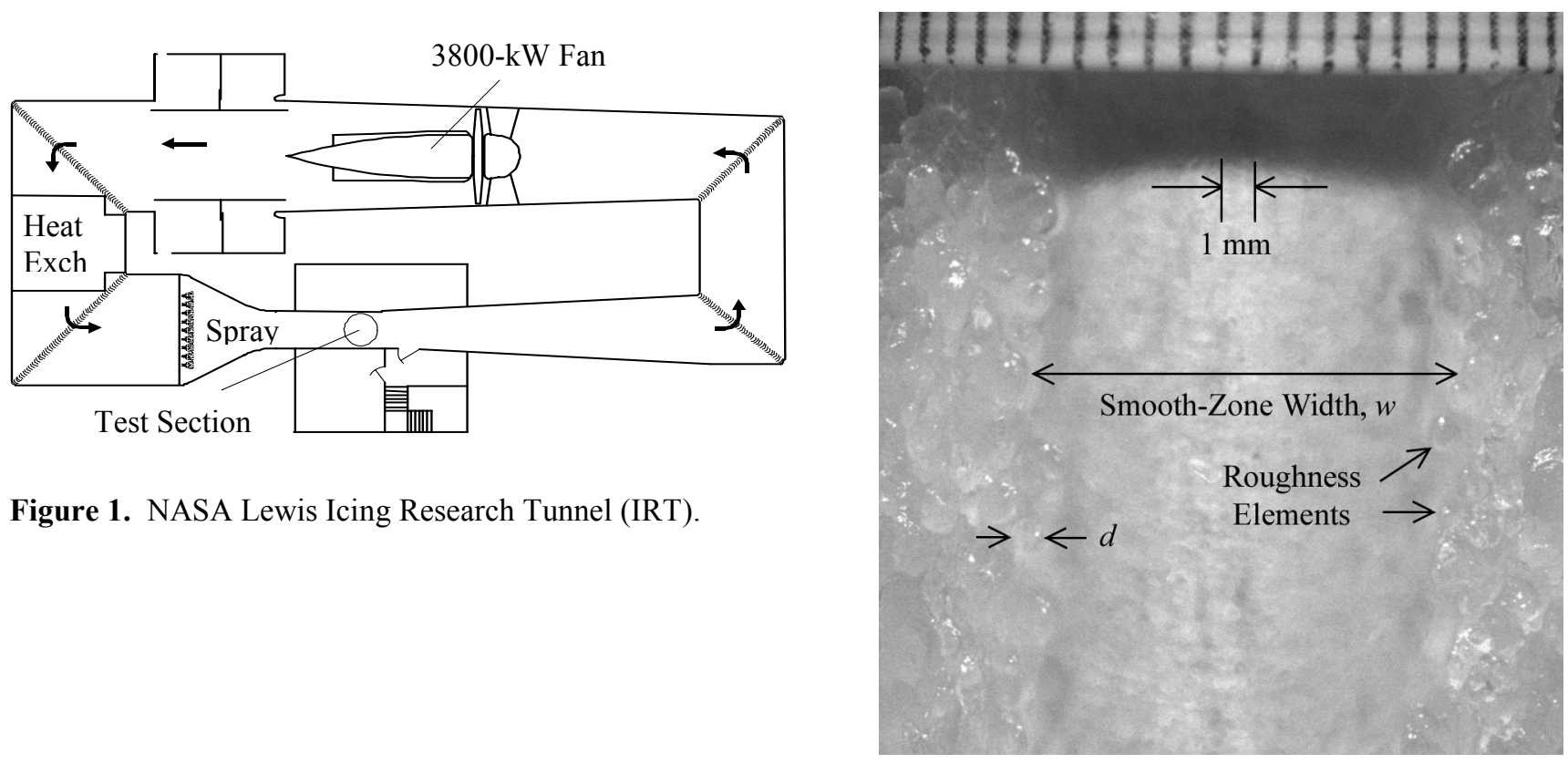

Figure 1. NASA Lewis Icing Research Tunnel (IRT).

Figure 2. Typical Image of Roughness Characteristics. 6-10-96 Run 8.

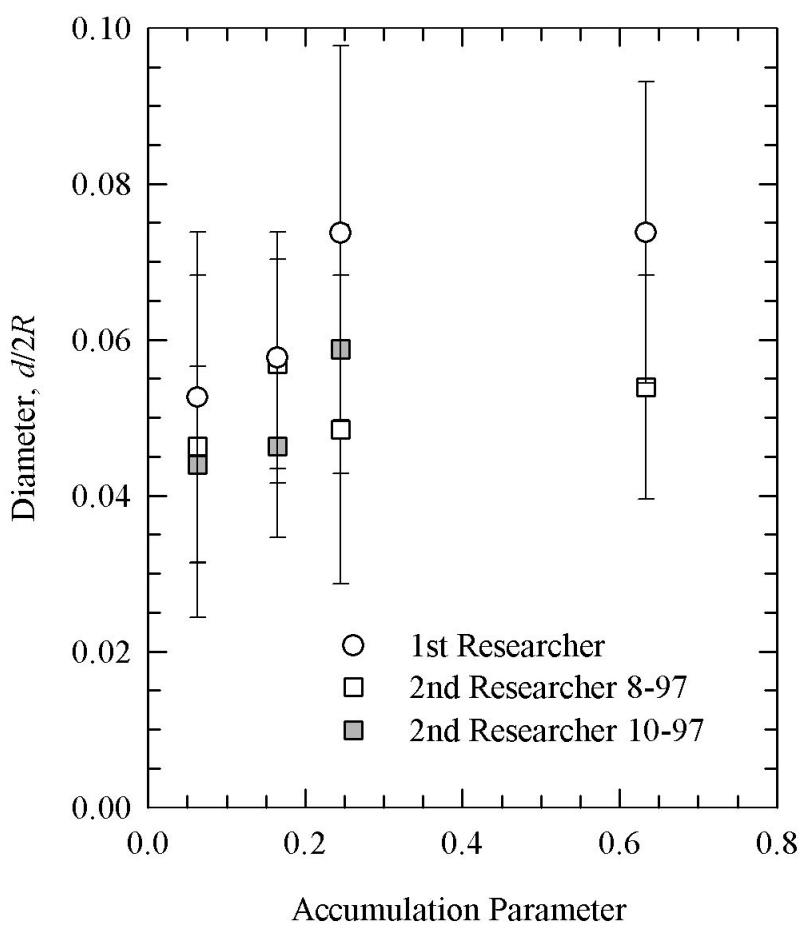

(a) Comparison of Three Independent Image Analyses.

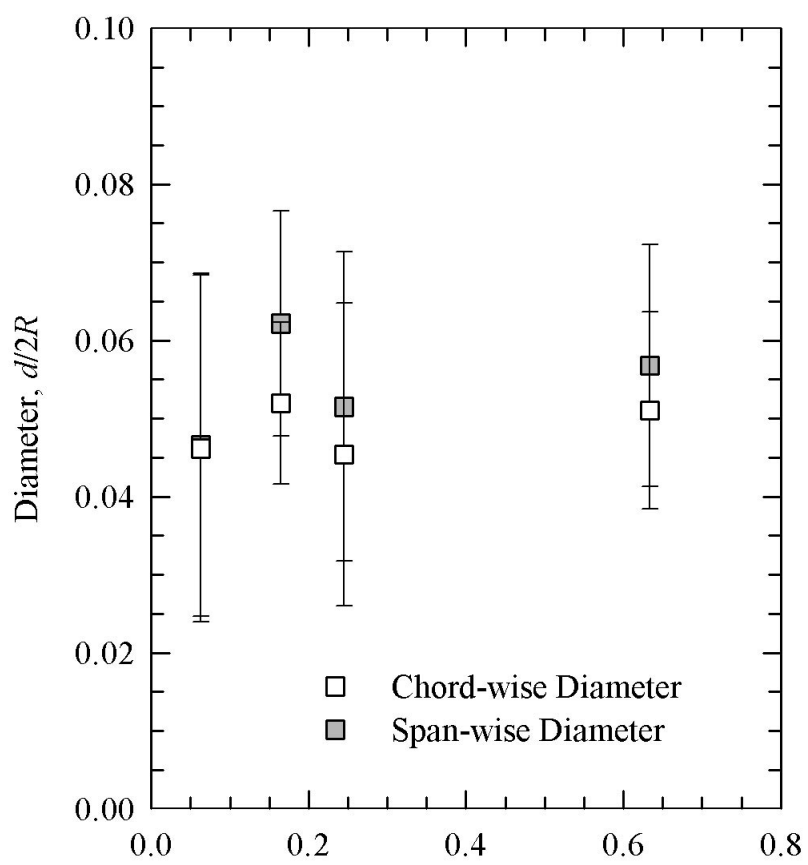

(b) Comparison of Element Diameters Measured in Chord-wise and Span-wise Directions.

Figure 3. Element Diameter Measurement Consistency. 5-29-96 Runs 1, 3, 4, 7. 


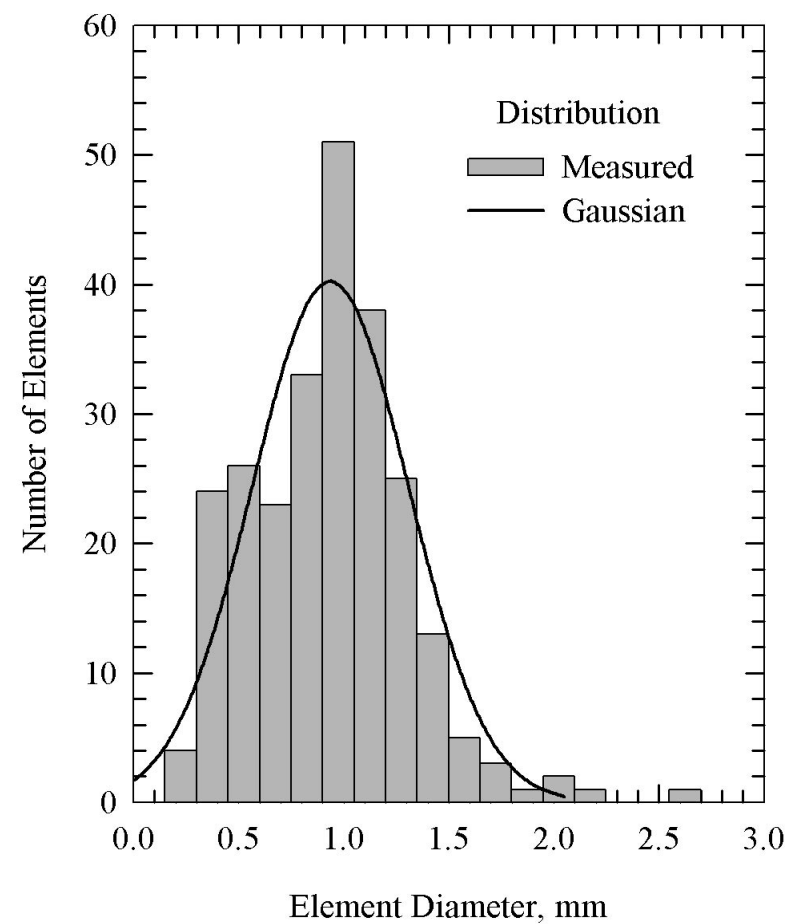

(a) Data for 5-29-96 Run 4.

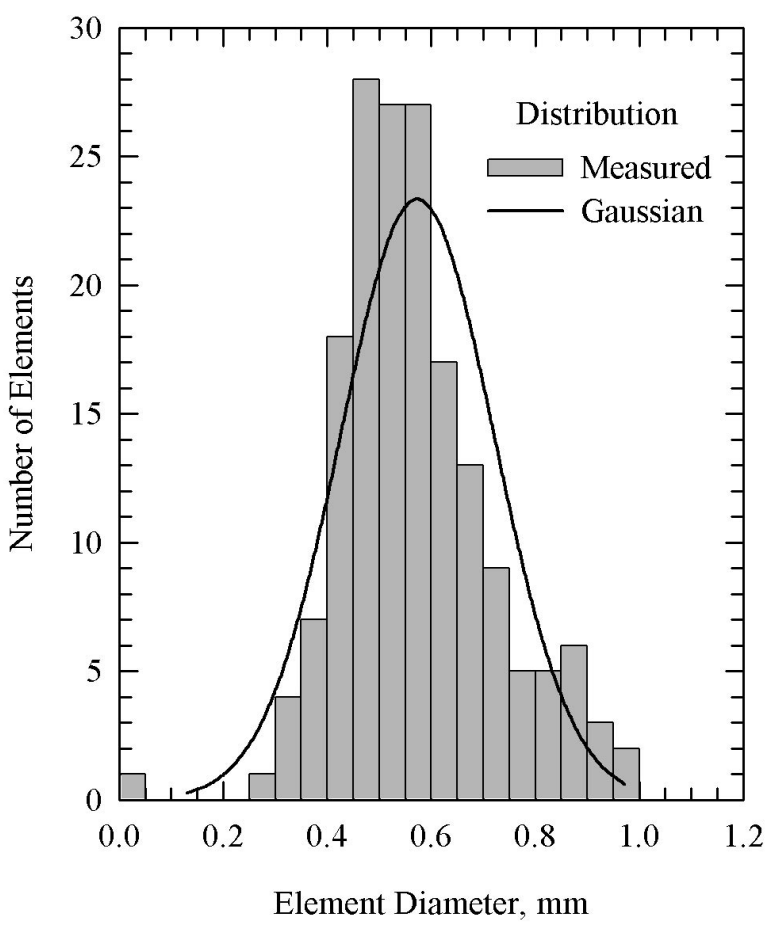

(b) Data for 5-30-96 Run 1.

Figure 4. Typical Roughness-Element Diameter Distribution.

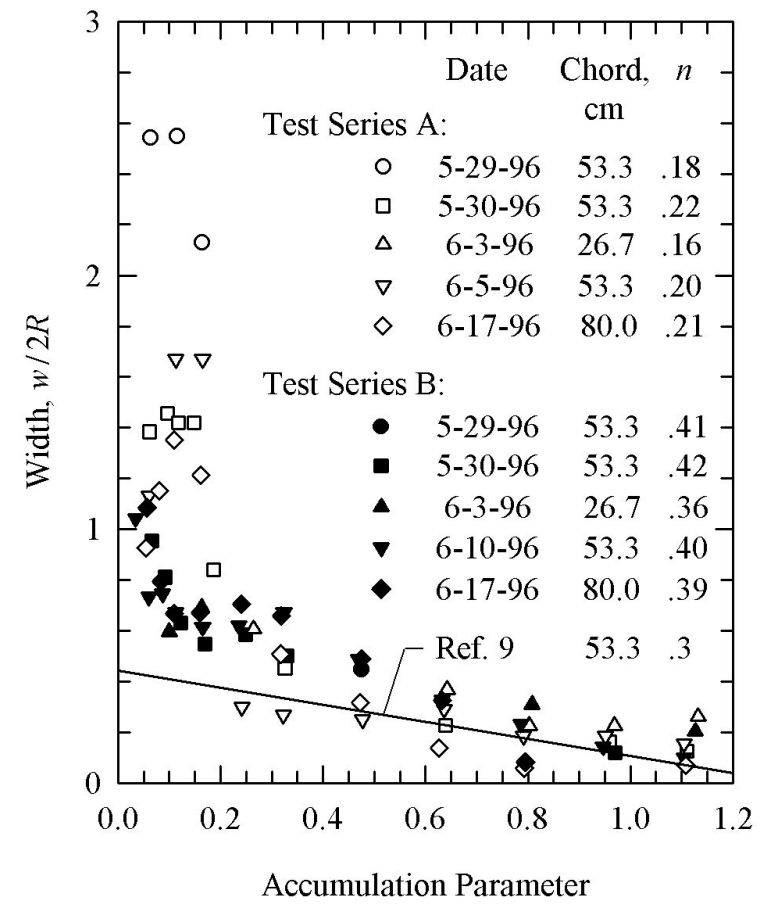

Figure 5. Smooth-Zone Width.

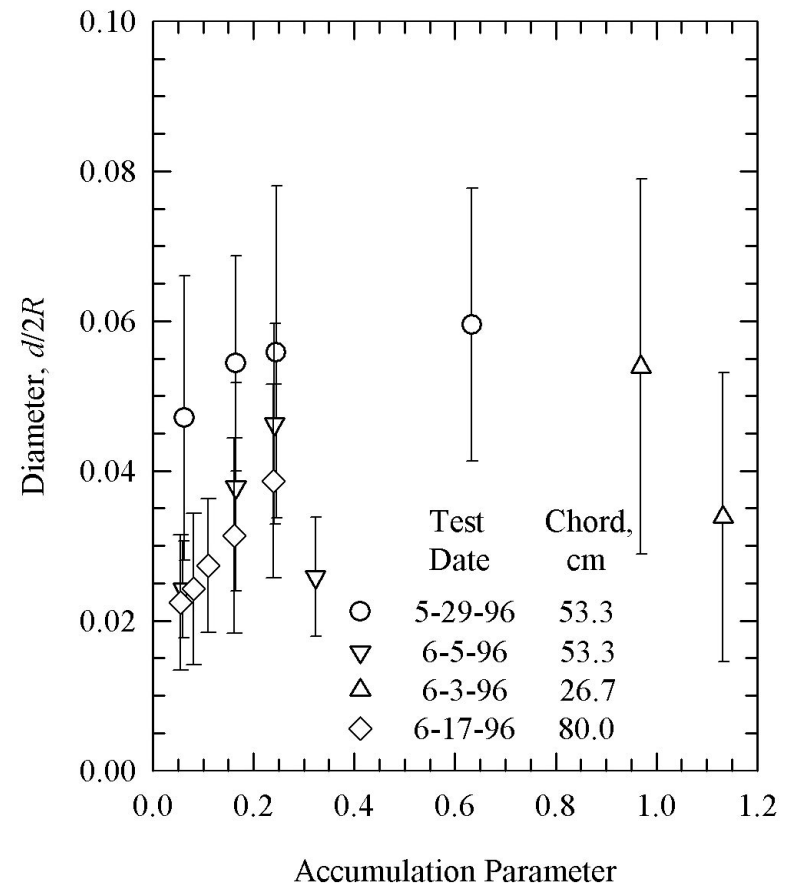

(a) Scaling Model Size for Test Series A. $n \approx 0.2$.

Figure 6. Roughness Element Size. 


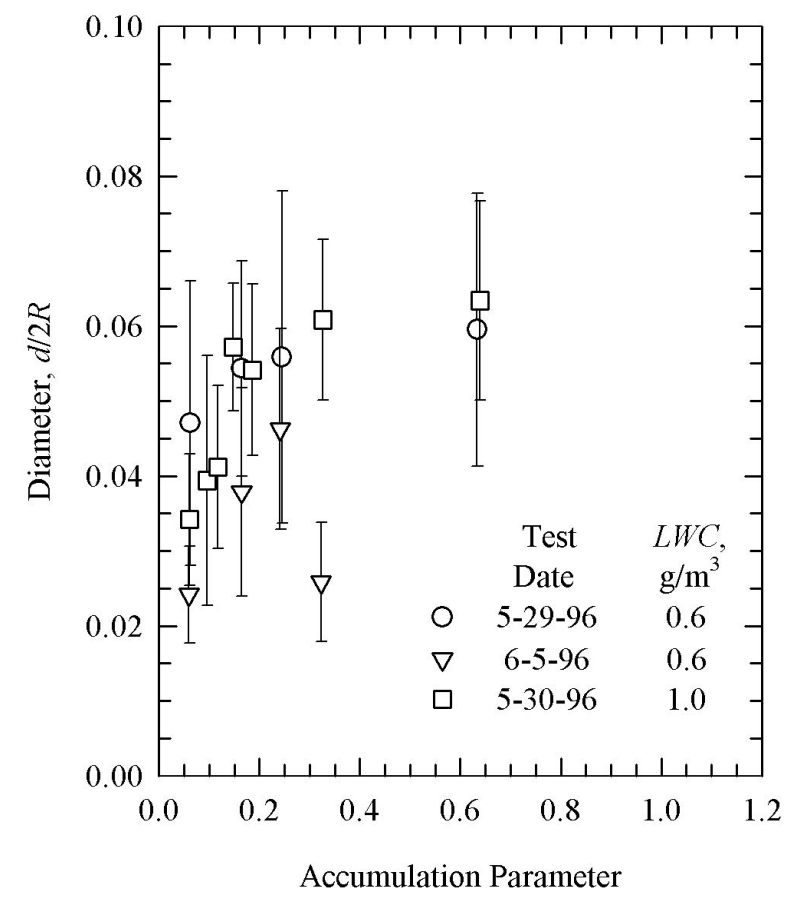

(b) Scaling Liquid Water Content for Test Series A. $n \approx 0.2$.

Figure 6. (concluded)

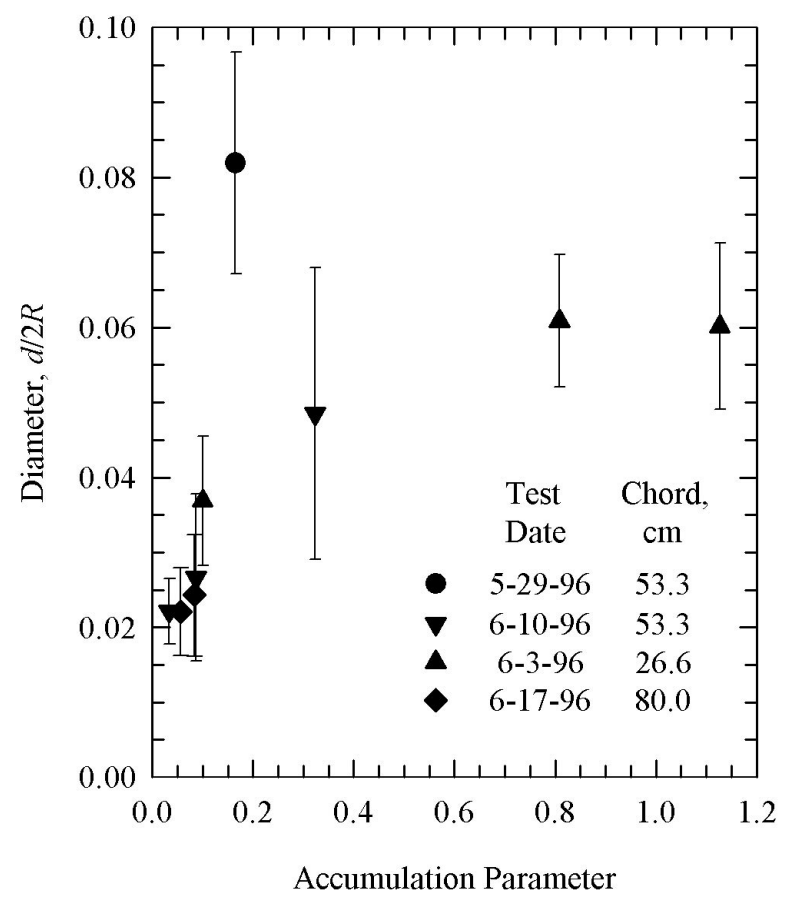

(c) Scaling Model Size for Test Series B. $n \approx 0.4$. 


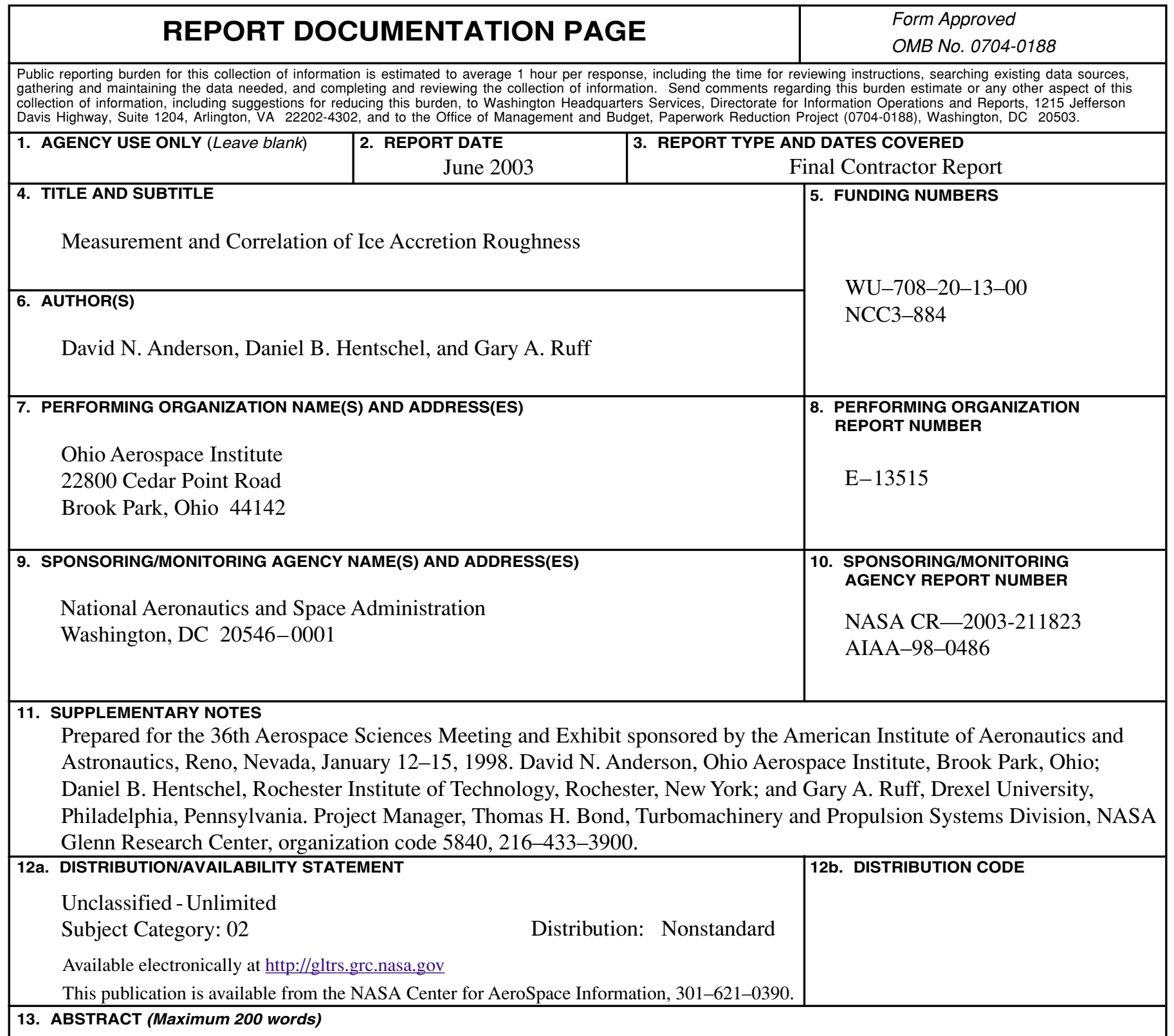

Measurements were taken of the roughness characteristics of ice accreted on NACA 0012 airfoils in the NASA Glenn Icing Research Tunnel (IRT). Tests were conducted with size scaled, using models with chords of $26.7,53.3$, and $80.0 \mathrm{~cm}$, and with liquid-water content scaled, both according to previously-tested scaling methods. The width of the smooth zone which forms on either side of the leading edge of the airfoil and the diameter of the roughness elements are presented in non-dimensional form as functions of the accumulation parameter. The smooth-zone width was found to decrease with increasing accumulation parameter. The roughness-element diameter increased with accumulation parameter until a plateau was reached. This maximum diameter was about 0.06 times twice the model leading-edge radius. Neither smoothzone width nor element diameter were affected by a change in freezing fraction from 0.2 to 0.4 . Both roughness characteristics appeared to scale with model size and with liquid-water content.

\begin{tabular}{|c|c|c|c|}
\hline \multicolumn{3}{|l|}{ 14. SUBJECT TERMS } & $\begin{array}{r}\text { 15. NUMBER OF PAGES } \\
20 \\
\end{array}$ \\
\hline $\begin{array}{l}\text { 17. SECURITY CLASSIFICATION } \\
\text { OF REPORT }\end{array}$ & $\begin{array}{l}\text { 18. SECURITY CLASSIFICATION } \\
\text { OF THIS PAGE }\end{array}$ & $\begin{array}{l}\text { 19. SECURITY CLASSIFICATION } \\
\text { OF ABSTRACT }\end{array}$ & 20. LIMITATION OF ABSTRACT \\
\hline Unclassified & Unclassified & Unclassified & \\
\hline
\end{tabular}

